OPEN ACCESS

Edited by:

Allen C. Meadors,

The Global Leadership Group,

United States

Reviewed by:

Warren G. McDonald,

Methodist University,

United States

Timothy Lynn Taylor,

Retired, Rockville, MD,

United States

*Correspondence:

Suena H. Massey

suena.massey@northwestern.edu

Specialty section:

This article was submitted to Public Health Education and Promotion,

a section of the journal

Frontiers in Public Health

Received: 14 July 2017

Accepted: 23 August 2017

Published: 19 September 2017

Citation:

Massey SH, Decety J, Wisner KL and Wakschlag LS (2017) Specification of Change Mechanisms in Pregnant

Smokers for Malleable Target Identification: A Novel Approach to a Tenacious Public Health Problem.

Front. Public Health 5:239.

doi: 10.3389/fpubh.2017.00239

\section{Specification of Change Mechanisms in Pregnant Smokers for Malleable Target Identification: A Novel Approach to a Tenacious Public Health Problem}

\author{
Suena H. Massey ${ }^{1,2 *}$, Jean Decety ${ }^{3}$, Katherine L. Wisner ${ }^{1}$ and Lauren S. Wakschlag ${ }^{2,4}$ \\ 'Department of Psychiatry and Behavioral Sciences, Northwestern University Feinberg School of Medicine, Chicago, IL, \\ United States, ${ }^{2}$ Institute for Innovations in Developmental Sciences, Northwestern University, Evanston, IL, United States, \\ ${ }^{3}$ Department of Psychology, University of Chicago, Chicago, IL, United States, ${ }^{4}$ Department of Medical Social Sciences, \\ Northwestern University Feinberg School of Medicine, Chicago, IL, United States
}

Maternal smoking during pregnancy (MSDP) continues to be a leading modifiable risk factor for perinatal complications and a range of neurodevelopmental and cardiometabolic outcomes across the lifespan. Despite 40 years of intervention research less than one in five pregnant smokers who receive an intervention quit by delivery. Within this context, recognition of pregnancy is commonly associated with abrupt suspension or reduction of smoking in the absence of intervention, yet has not been investigated as a volitional target. The goal of this article is to provide the empirical foundation for a novel direction of research aimed at identifying malleable targets for intervention through the specification of behavior change mechanisms specific to pregnant women. To do so, we: (1) summarize progress on MSDP in the United States generated from conventional empirical approaches to health behavior change; (2) discuss the phenomenon of spontaneous change in the absence of intervention among pregnant smokers to illustrate the need for mechanistic specification of behavior change motivated by concern for fetal well-being; (3) summarize component processes in neurobiological models of parental and non-parental social behaviors as a conceptual framework for understanding change mechanisms during pregnancy; (4) discuss the evidence for the malleability of these processes to support their translational relevance for preventive interventions; and (5) propose a roadmap for validating the proposed change mechanism using an experimental medicine approach. A greater understanding of social and interpersonal processes that facilitate health behavior change among expectant mothers and how these processes differ interindividually could yield novel volitional targets for prenatal interventions. More broadly, explicating other-oriented mechanisms of behavior change during pregnancy could serve as a paradigm for understanding how social and interpersonal processes positively influence health behaviors across the lifespan.

Keywords: pregnancy, smoking cessation interventions, addiction, empathy, attachment, oxytocin, OXTR, behavior change 


\section{HEALTH BEHAVIORS ARE DIFFICULT TO CHANGE}

Despite substantial research, maternal smoking during pregnancy (MSDP) continues to be a leading modifiable contributor to low-birth weight, a robust risk factor for adverse neonatal, neurodevelopmental, metabolic, and cardiovascular outcomes across the lifespan (1). The year 2017 marks the 40th anniversary since publication of the first prenatal smoking cessation intervention trial (2). Since this time, 96 randomized controlled intervention trials (RCTs) including over 31,000 pregnant smokers, testing 37 individual behavior change techniques $(3,4)$, and an additional 26 qualitative studies $(5,6)$ have led to important but modest gains. In the United States, the prevalence of MSDP fell most dramatically in the 1990 s from 17.3 to $13.3 \%$. However, in the following decade, the prevalence fell by just 1 to $12.3 \%$ in 2010 (7). This means that one in nine infants in the United States is born prenatally exposed to MSDP. This figure is as high as one in four for infants born to socioeconomically disadvantaged women and women from marginalized populations $(7,8)$. On average, intervention increases the chances a pregnant smoker will stop smoking before delivery by only 6\% (4). Even for interventions involving financial incentives for biologically verified abstinence, well under half of pregnant smokers achieve abstinence by delivery (9). Intervention-especially financial-incentive-based interventions-are associated with improved birth outcomes (10). However, to achieve the goal of $1 \%$ prevalence in MSDP set by Healthy People 2020, an infusion of novel approaches is imperative (11).

With this goal in mind, we reflect on MSDP within the broader challenge of promoting healthy lifestyles in the general population that spans at least a half a century (12). Following the development of 83 largely overlapping theories of behavior change comprising more than 1,000 constructs and 23 different intervention targets (13), the leading causes of morbidity and mortality in the United States continue to be directly attributable to lifestyle behavior, namely, smoking, poor diet, and inactivity $(14,15)$. For example, when we consider that obesity has become more rather than less prevalent during this time, and is presenting earlier in life in the United States $(16,17)$, the progress made on reducing MSDP seems outstanding in comparison. And this is hardly surprising.

Pregnancy itself elicits abrupt temporary change in smoking behavior without formal intervention and does so more effectively than any intervention strategy tested to date (18). The presence of an other-oriented mechanism of change-concern about the unborn child-is well-documented in qualitative (5) and quantitative studies $(3,19,20)$, yet remains poorly understood. This unique interpersonal aspect of MSDP could represent a powerful volitional target for intervention.

We describe a novel conceptual framework for mechanistic research on health behavior change motivated by concern for others, as is observed in pregnant smokers. Foundational to the proposed framework are cognitive, affective, motivational, and regulatory processes described in emerging neurobiological models of human caregiving behavior and how these processes interact dynamically with addictive processes. We illustrate the potential utility of this proposed mechanism, if validated, for intervention development and personalization of treatment. We conclude by outlining a roadmap for empirical validation of the proposed mechanism and its application to intervention development. A systematic review of the literature is not the aim of this article-we refer readers to recent high-quality systematic reviews of prenatal smoking cessation intervention studies (3); qualitative studies on $\operatorname{MSDP}(5,6)$; and other relevant topics throughout this article.

\section{WHY STUDY CHANGE MECHANISMS?}

Traditionally, health behavior change research has involved efficacy trials aimed at modifying one or more targets identified from behavior change theories [for a full taxonomy of these theories see Ref (13).]. In recent years, recognition of the limitations and inefficiency of this approach has fueled interest in an Experimental Medicine (EM) approach that prioritizes a mechanistic understanding of putative targets prior to conducting full efficacy trials (21). Clearly elucidated mechanisms of change enable scientists to conclude why a particular intervention worked or failed to work in a given study and affords the opportunity to translate knowledge gained from one particular trial to other contexts, behaviors, or populations (13). Moreover, behavior change theories are limited by (a) a lack of specification of population and context (i.e., in what populations or contexts are theories and targets identified by theories most predictive of behavior change); (b) a lack of are specification of volitional factors (why people would want to change in the first place); (c) the inability to infer how change in targets over time influences behavior since theories are derived primarily from correlational evidence; and (d) the rare examination of affective processes as putative targets for interventions (22).

Lack of specification is reflected in the U.S. Preventive Services Task Force's (USPSTF) recommendation for "Tobacco Smoking Cessation in Adults, Including Pregnant Women" using the 5 A's intervention (Ask, Assess, Advise, Assist, and Arrange). The extent of specification for pregnant women involves (a) behavioral rather than pharmacologic interventions and (b) ensuring educational materials about risk are pregnancy-specific $(23,24)$. There are clearly overlaps in barriers to smoking cessation among non-pregnant and pregnant women. These include stress and its psychopathological manifestations $(25,26)$, limited internal and external resources $(27,28)$, and smoking-related factors $(29,30)$. However, smoking cessation among pregnant women is also associated with unique volitional factors. It is externally- rather than internally-motivated and appears to be temporary $(19,31)$. Yet, these unique factors have not been adequately explicated as change mechanisms.

\section{OTHER-ORIENTED CONCERN AS A PUTATIVE TARGET FOR BEHAVIOR CHANGE INTERVENTIONS}

The term "spontaneous quitters" has been used to describe a substantial subset of pregnant smokers-some $40-65 \%$ of 
privately insured smokers and $11-28 \%$ of smokers in publicly funded obstetric clinics-who stop smoking without intervention in early pregnancy and prior to the onset of obstetric care in the United States. The prevalence of spontaneous quitting is remarkably similar across the United Kingdom and other European countries $(32,33)$. Spontaneous quitters have lower smoking-related risks (i.e., nicotine dependence, partner smoking, age of smoking initiation, impulsivity) and comparatively favorable demographic profiles (being married, more highly educated, and nulliparous) (34). However, there is converging evidence that unmeasured factors or processes beyond the mere absence of risks facilitate sustained abstinence among spontaneous quitters.

First, spontaneous quitters achieve abstinence rates two to three times higher than non-pregnant women who quit "cold turkey" over a similar period of time $(65-81 \%$ across gestation when biochemically verified) (34-36). Spontaneous quitters' abstinence rates also compare favorably to other highly motivated populations including men and women who recently suffered a heart attack $(37,38)$. Moreover, spontaneous quitters report greater confidence about their ability to remain abstinent for the duration of pregnancy relative to non-pregnant quitters over the same period of time, yet do not use the behavioral strategies (i.e., coping skills, distractions, oral-substitutes) used by successful recent ex-smokers (39).

Even women who make adoption placements at birth report suspending tobacco, alcohol, and illicit drug use at rates comparable to rates reported in epidemiologic samples $(28,40,41)$. This suggests that mechanisms that facilitate spontaneous quitters' success are at least partially attributable to being pregnant, distinct from factors associated with the transition to parenthood (42). Moreover, these mechanisms may apply to other addictive behaviors besides cigarette smoking (43). Consistent with this are findings by Curry and colleagues (31) that pregnant smokers endorse different motives for abstinence from smoking during pregnancy, i.e., "I want to be healthy for my baby," versus abstinence during the postpartum period "I do not want to be known as a smoker by my child" $(31,44)$.

Finally, the mechanisms that facilitate spontaneous quitting could reflect a broader pattern of harm reduction. Substantial inter- and intra-individual fluctuation in smoking across gestation has been documented in quantitative studies of pregnant women (45). In qualitative studies, many women who do not abstain from smoking during pregnancy reduce their smoking early in pregnancy with the stated intent of reducing harm to the fetus (since quitting altogether is not perceived as possible) $(3,46$, 47). Additionally, the power of the imagined harm to the fetus caused by continued smoking during gestation is evidenced by intense guilt reported by women who cut down but do not abstain (5). In one of the largest studies specifically focused on spontaneous quitting which included 118 spontaneous quitters and 231 continuing smokers, the belief that "smoking will greatly harm my baby" was associated with a 14-fold increase in the likelihood of being a spontaneous quitter (27). In summary, in the absence of intervention, "being pregnant" seems to positively influence smoking trajectories via temporary suspension and reduction of smoking. Elucidating this change mechanism and how it can be amplified can yield new avenues for improving the immediate and long-term health of mothers and their children.

To do so, we take an interdisciplinary approach that blends advances in social neuroscience (48), parenting neurobiology (49), and the interruption of parenting processes by addiction (50). Drawing from these literatures, we hypothesize that key cognitive, affective, motivational, and regulatory processes that facilitate responsive caregiving behavior, as characterized across separate theoretical foundations (51-53), may be highly relevant for identifying putative targets for intervention during pregnancy. Moreover, we illustrate how this developmental framework, if validated, can be used to personalize interventions. Finally, we describe a detailed research agenda aimed at validating the proposed mechanism.

\section{MODELS OF CAREGIVING BEHAVIOR}

Striking similarities in the mechanisms of affiliation and maternal caregiving behavior across mammalian species and their modulation by the neuropeptide hormone oxytocin support their highly conserved role in survival, adaptation, and evolution (54). In recent decades, functional magnetic neuroimaging (fMRI) studies in human parents presented with simulated cues salient to caregiving (i.e., infant faces, cries, and odors) have facilitated the identification of a network of neural regions implicated in parental caregiving commonly referred to as a parenting network, parenting circuitry, or the "parental brain" [for a recent review of these fMRI studies, see Ref (55)]. Optimal spatial resolution offered by fMRI is nicely complemented by temporally sensitive neuroimaging techniques such as electroencephalography (EEG) with event-related potentials (ERPs) and magneto-encephalography from which processing functions of specific neural structures may be inferred. For example, the temporal sequence of signals following an experimental stimulus is used to infer sensory perception, detection of salience, and attentional processes, followed by "top-down" regulation and reappraisal (56). Neural processes associated with parenting behavior, combined with their regulation by oxytocinergic, hypothalamic-pituitary-adrenal axis and autonomic functions are referred to, collectively, as the caregiving system $(49,51)$. This system is also thought to regulate altruistic (other-oriented) prosocial (helping) behaviors outside of the parenting context (51, 57-59).

Common to both sensitive parenting behavior and prosocial behavior is empathy (60), defined here, as the ability to perceive others' need, coupled with a motivation to help $(61,62)$. Different definitions of empathy within and across scientific disciplines have created confusion, detracting from its highly conserved and critical role in social behavior $(48,58,63)$. The dual function of empathy-related mechanisms in promoting other-oriented responding while regulating internal stress responses is, however, increasingly recognized (though not explicitly) by intense inquiry regarding the therapeutic potential of its biological substrate, oxytocin $(48,49,64)$. For heuristic purposes, we will use the terms, caregiving processes and empathic processes interchangeably to refer collectively, to the perceptual, affective, motivational, and regulatory processes necessary for the expression of behavior aimed at helping others in parental and non-parental contexts, 
respectively. Specific cognitive and affective facets of empathy (i.e., affective sharing, empathic concern, perspective taking or cognitive empathy, and personal distress) will also be defined herein to illustrate how they map onto perceptual, affective, motivational, and regulatory processes described in parental caregiving models.

\section{SPECIFIC PROCESSES THAT FACILITATE CAREGIVING}

The component processes involved in parental caregiving behavior may be broadly characterized as: (a) the perception of cues signaling need or distress in another; (b) affective processing of these cues; (c) competing other-oriented versus self-oriented motivational states; and (d) subsequent behaviors (to help versus to withdraw) moderated by internal regulatory capacity $(51,65$, 66). Below, we elaborate on these processes and describe how they may facilitate motivation to reduce or suspend smoking following the recognition of pregnancy.

\section{Perception of Others' Need or Distress}

The ability to detect distress in others (and the subsequent motivation to help) is observable in young children including infants prior to the development of more complex social cognitive abilities $(62,67,68)$. Qualitative studies suggest that the recognition of a pregnancy is a highly salient event (69). As fetal needs are perceived in abstract terms, rather than seen or heard as is the case with infant cues following delivery, the capacity and tendency to imagine others' perspective, described by the construct perspective taking (58), could influence the degree to which caretaking processes are activated in pregnant smokers. In fact, there is preliminary evidence for the role of perception of others' distress in MSDP. Among women who possess OXTR variants previously associated with increased sensitivity to social cues $(70,71)$, the ability to accurately identify distress in others has been associated with lower levels of biochemically assessed smoking across pregnancy (72). Following the perception of need in others, subsequent affective processing of this information critically predicts divergent behavioral responses. This is described in models of social behavior derived from research on parenting neurobiology, social neuroscience, and human attachment and affiliation described below.

\section{Affective Processing of Cues Signaling Others' Need or Distress \\ Affective Processing in the Parental Caregiving System}

Rodent models of caregiving support the roles of specific nuclei in the hypothalamus and oxytocin in caretaking through (a) enhancing approach motivation (to help offspring in need) involving the nucleus accumbens-ventral pallidum reward circuit; while (b) inhibiting a competing avoidance motivation (to withdraw from offspring) by inhibiting the transmission of threat signals from the amygdala to the periaqueductal gray (73). A similar dynamic of competing motivations and their modulation by oxytocin has since been supported by neuroimaging studies in humans
$(74,75)$. In a particular RCT, intranasal oxytocin administration in mothers presented with infant stimuli was associated with increased insular activation (supporting caregiving processes), concomitant with reduced activation of the amygdala (involved in the processing of threat) (76). This competing dynamic of otheroriented versus self-oriented processes may be highly relevant for understanding the ambivalence verbalized by pregnant smokers, who describe the competing desires to reduce harm to the fetus, yet still maintain their own emotional stability by continuing to smoke $(5,6)$. The child development literature similarly acknowledges how parents' emotional control is tightly intertwined with cognitive control (i.e., executive function) that together, predict sensitivity of parenting behavior [for a review, see Ref (66)].

\section{Affective Processing in Social Neuroscience Models}

In affective neuroscience models, affective processing involves two functionally distinct processes-affective sharing and empathic concern-quantified using behavioral paradigms involving images of others' limbs in painful contexts (hand under a knife or a bare foot under a car tire) $(53,57)$. Affective sharing describes a reflexive somatovisceral resonance with others' pain while maintaining self-other distinction, corresponding to an early N200 signal on EEG/ERPs occurring within 160-220 ms following a stimulus. Affective sharing of others' pain results in activation of neural circuitry involved in one's own experience of pain as detected using fMRI, i.e., the anterior insula, anterior cingulate cortex, supplementary motor area, amygdala, somatosensory cortex, and periaqueductal gray $(61,77)$.

Broadly consistent with the concept of competing approach and avoidance motivations described in parental caregiving models (51), whether affective sharing leads to other-oriented empathic concern and motivation to help, versus self-oriented personal distress (58) and motivation to withdraw, is also thought to be dependent on top-down regulatory processes. Specifically, empathic concern is associated with a late positive potential on EEG/ERP, occurring 400-800 ms following stimulus presentation indicative of cognitive reappraisal and emotional regulatory processes $(78,79)$. There is also evidence that the capacity for perspective taking (imagining others' point of view) is associated with lower stress reactivity, whereas personal distress is associated with higher stress reactivity, respectively (80). This parallels mechanisms of stress attenuation that facilitate approach motivation described in the in caregiving system, and supports a dynamic interplay between stress and caregiving processes (81).

\section{Affective Processing in Attachment Research}

The closeness, or affiliation felt toward another, described by attachment, is another facet of affective processing hypothesized to influence smoking behavior during pregnancy. The neurobiological understanding of human parental attachment is derived from functional neuroimaging paradigms comparing neural responses to parents' own infant's stimuli to responses to other infants' stimuli $(82,83)$. There is broad recognition that attachment develops during gestation, termed maternal fetal attachment (84). Greater maternal fetal attachment in pregnant women has been linked to increasing plasma oxytocin levels across gestation (85), more positive health-related behaviors during pregnancy 
[see Ref (86) for a review], including smoking cessation during pregnancy (20) and consumption of fewer cigarettes per day among persistent pregnancy smokers (87).

Maternal-child attachment is thought to emerge from mothers' thoughts and fantasies about their children, called representations (88), beginning during pregnancy (i.e., prenatal representations) (89), assessed by structured interviews (90). Prenatal representations could provide an avenue for improving maternal fetal attachment, and putatively, health-related behaviors. In attachment-theory-based research, cognitive empathic abilities are described by reflective function and mind-mindedness. Reflective function describes the capacity to accurately interpret others' non-verbal cues enabling sensitive and contingent responding to others' needs (91). Intact reflective function requires mindmindedness or the ability to interpret others' behaviors in the context of their thoughts and emotions. Mothers who possess mind-mindedness are able to imagine thoughts and emotions in their children that govern their behaviors (92). Within this theoretical framework, underlying mechanisms of unresponsive or deficient parenting (i.e., neglect, use of harsh disciplinary practices) among mothers with substance use disorders are beginning to be elucidated.

\section{HOW ADDICTIVE PROCESSES MAY INTERACT WITH CAREGIVING PROCESSES}

\section{Impaired Caregiving in Mothers with Substance Use Disorders}

Women who smoked persistently during pregnancy (in the absence of illicit substance abuse) are also more likely to exhibit harsh parenting practices though the underlying mechanisms are not well elucidated $(93,94)$. Research on mothers with cocaine and opiate use disorders, however, provides possible explanations (95). Studies have shown that impaired reflective function in these mothers $(91,96)$ underlies maltreatment and neglect (97). Differences in the regulation of reward and stress have also been posited as explanations in light of the substantial overlap in neural circuitry implicated in parenting behavior, reward processing, and regulation of stress (98). Substance-using mothers exhibit reduced activation in parenting circuitry when presented with infant cues suggestive of an attenuated empathic response $(99,100)$. These findings are broadly consistent with neurobiological models of addiction in which socially salient cues fail to signal reward due to drug-induced allostatic modifications related to prolonged drug exposure $(101,102)$. In this way, parenting cues that might normally activate reward pathways in non-using mothers may alternatively trigger stress responses in addicted mothers and increase vulnerability to relapse as a form of coping (98).

\section{Structural and Functional Alterations in Empathic Processing in Non-Pregnant Smokers and Substance Users}

There is converging evidence for impaired social information processing in non-pregnant smokers and substance abusers though whether impairments are a cause or consequence of smoking and substance use (or some combination) is unknown [for a reviews see Ref $(103,104)$ ]. Chronic heavy smokers show reduced gray matter volume in empathic processing regions relative to individuals who never smoked (103). Resting-state functional connectivity in the anterior insula-ventromedial prefrontal cortical circuit also differs among non-pregnant individuals with and without nicotine dependence (105). Weakened connectivity in this circuit fully mediated a found link between alexithymia (inability to describe one's own emotions) and cigarette craving in one study of 24 smokers and 20 non-smokers (106). Deficits in affective and cognitive empathy have also been documented in a number of cross-sectional studies of non-pregnant women and men with alcohol, cocaine, and methamphetamine use disorders, with unclear directionality in the addiction-empathy link (104).

If pregnant smokers have impairments in empathy as might be suggested by these studies, according to the hypothesized caregiving mechanism, cues salient to caregiving such as the recognition of pregnancy or advice from providers to quit, may not be processed in the same way as in women who never smoked. This could also explain the apparent resilience to intervention observed among pregnant smokers who smoke heavily (107). Namely, the motivation to protect the fetus-assumed to be present in all pregnant smokers, may actually be attenuated due to neuroadaptations related to chronic smoking itself, rendering heavy smokers no more likely to quit than non-pregnant individuals $(103,105)$. We go one step further to illustrate how a caregiving mechanism could explain individual differences in responses to interventions.

\section{How Processing Differences Might Explain Varied Responses to MSDP Interventions}

An interaction between nicotine dependence and motivation to quit smoking was suggested by Stotts and colleagues in their 2009 study that tested an innovative 30-min therapeutic fetal ultrasound session (U/S). The U/S session was aimed at providing a biological marker of risk hypothesized to increase motivation for smoking cessation (108). Arms of this intervention trial were: (a) U/S with motivational interviewing (U/S + MI); (b) U/S with the best practices 5 A's intervention $(\mathrm{U} / \mathrm{S}+\mathrm{BP})$; and (c) the 5 A's alone (BP) (109). Differences in cessation rates by intervention group were not found for the entire sample of $N=360$ pregnant smokers.

However, post hoc analyses showed that women who smoked less than 10 cigarettes/day (light smokers) appeared to benefit from the U/S intervention; cessation rates for $\mathrm{U} / \mathrm{S}+\mathrm{MI}, \mathrm{U} / \mathrm{S}+\mathrm{BP}$, and $\mathrm{BP}$ alone were $34,25.8$, and $15.6 \%$, respectively. For women smoking 10 or more cigarettes/day (heavy smokers), cessation rates were $0 \%$ for $\mathrm{U} / \mathrm{S}+\mathrm{MI}, 2.3 \%$ for $\mathrm{U} / \mathrm{S}+\mathrm{BP}$, and $7 \%$ for $\mathrm{BP}$ alone. Thus, heavy smokers who received U/S appeared to be less likely to quit smoking relative to heavy smokers receiving the less intensive 5 A's intervention. Authors hypothesized that the U/S could have had an opposite effect as intended-of reassuring smokers about the well-being of the fetus.

Interpreting these results using a caregiving framework, we posit that for heavy smokers, visualization of the fetus during the $\mathrm{U} / \mathrm{S}$ (a visual cue salient to caregiving) failed to elicit its intended 
effect on smoking behavior due to attenuated empathic responding, much as neural responses to infant stimuli are attenuated among smoking and substance-abusing mothers (99, 100). On the other hand, applying the model of competing approach versus avoidance motivation described in the caregiving model (51), it is also conceivable that the U/S intervention had the effect of enhancing self-oriented personal distress and guilt associated with continued smoking in heavy smokers rather than promoting other-oriented motivation to quit (6) as intended. This could have led to continued smoking to cope with guilt. Fortunately, there is growing support for the malleability of empathic processes via behavioral interventions.

\section{EVIDENCE FOR THE MALLEABILITY OF EMPATHIC PROCESSES}

\section{Attachment-Based Interventions to Increase Reflective Function}

Parenting interventions designed to target impaired reflective function [i.e., Minding the Baby (110)] are effective for improving the sensitivity of subsequent parenting behavior, the quality of mother-child interactions, reward experienced by mothers when interacting with their children, and also the chances of maintaining abstinence from drug use $(111,112)$. Results from these programs support not only the malleability of empathic processes, then, but also the possibility that attachment processes effectively compete with addictive processes.

\section{Mindfulness-Based Interventions That Increase Empathy}

There is intense interest in mindfulness-based interventions for smoking cessation and substance misuse $(113,114)$. One particular mindfulness-based exercise aimed at promoting caring and compassion toward oneself and others called loving kindness mediation (LKM) may hold promise for MSDP if hypothesized change mechanisms are validated. Based on recent reviews of this young literature, LMK appears to improve perceived well-being, biological markers of stress, and behavioral control in non-pregnant individuals through increases in positive emotions and empathy (115-117). The impact of LKM on a range of outcomes seems robust with minimal intervention. A recent study showed that simply listening to LKM language once, without actually mediating, increased both reported empathy and ratings of sensitivity to others' pain when compared to a control condition that involved exposure to similar language but replaced words connoting love with words connoting physical safety and security (118).

\section{Experimental Pharmacologic Interventions in Non-Pregnant Individuals}

The documented effects of pharmacologic interventions aimed at increasing empathy, while not necessarily appropriate for pregnant women, provide further support for the malleability of caregiving and empathic processes. In a growing number of studies of non-pregnant healthy and disease populations, one-time administration of intranasal oxytocin seems to increase empathic ability, prosocial behaviors, and to reduce stress reactivity. The underlying mechanisms and safety of intranasal oxytocin has yet to be established, however, even for healthy non-pregnant individuals [Ref. (119), for a review]. Nonetheless, there is also increasing interest in how therapeutic interventions involving oxytocin could be used in the treatment of addiction. Intranasal oxytocin administration in non-pregnant smokers has been shown to reduce cue-elicited craving (120) suggesting that the interaction between affiliative processes and addictive processes may be bidirectional $(104,121)$. Intranasal oxytocin also reduces craving and stress responses in marijuana-dependent individuals (122), reduces drug-seeking among cocaine dependent individuals (123), and reduces withdrawal symptoms and benzodiazepine requirements among alcohol dependent individuals (124). Similar effects have also been observed with exogenous administration of 3,4-methylenedioxymethamphetamine (MDMA), commonly known as the recreational drug, ecstasy (125). Finally, polymorphisms in the oxytocin receptor gene (OXTR) previously linked to sensitivity to social context (126-128), and implicated in MSDP (72), appear to predict which individuals will respond most robustly to all three of the aforementioned empathy-enhancing modalities (LKM, oxytocin, and MDMA), raising the possibility of a personalized approach to MSDP in the future.

\section{THE EXPECTANT BRAIN AS THE NEXT HORIZON IN PREVENTION}

Whether and to what extent the caregiving processes described in parents occur during pregnancy is not clear due to the relative paucity of clinical research studies conducted in pregnant women (129). However, tremendous plasticity observed during the early postpartum period (130) and the prediction of maternal-infant attachment by maternal-fetal attachment and plasma oxytocin during pregnancy support the emergence of caregiving processes prenatally (85). There is also early evidence that pregnant women show heightened vigilance to novelty and threat cues close to delivery when compared with non-pregnant women (131-133).

The most compelling evidence for prenatal neuroadaptions to caregiving comes from a recent longitudinal structural MRI study. Comparison of pre-pregnancy and postpartum scans showed reductions in gray matter volume in regions implicated in social information processing (i.e., the theory of mind network) among primiparous pregnant women. These structural changes predicted observed and reported attachment to infants postpartum and were neither observed in women's male partners, multiparous pregnant women, nor in a comparison sample of non-pregnant women over the same period of time (134). These findings suggest that structural changes related to postpartum caregiving occur during a woman's first pregnancy but not in successive pregnancies. Could this observed neuroplasticity during a woman's first pregnancy facilitate spontaneous behavior change?

Increasingly sophisticated methods for assessing the maternal-fetal dynamic via fetal neurobehavioral assessments have led 
to a greater understanding of the complex mechanisms through which maternal mood and behavior during pregnancy influence fetal neurodevelopment and long-term developmental outcomes for children $(135,136)$. These approaches can also provide rich experimental and therapeutic opportunities for intervention on MSDP. Realizing the potential scientific gains from these diverse empirical frameworks, however, requires scientific collaboration that transcends disciplines and methodologic approaches (137). These disciplines include but are not limited to the science of behavior change, parenting and addiction neurobiology, attachment theory, social neuroscience, developmental psychology, and developmental neurobiology. With this spirit of interdisciplinary collaboration in mind, we present a research agenda for the application of this collective knowledge toward identifying novel targets for prenatal smoking cessation interventions.

\section{A ROADMAP FOR RESEARCH USING AN EM APPROACH}

The Science of Behavior Change working group of the National Institutes of Health recommends the following 4-step EM approach that focuses on the importance of understanding behavior change mechanisms prior to conducting efficacy trials (21).

(1) Identify a modifiable factor that relates to behavior as a putative target for intervention.

(2) Validate the putative target through the development of a multilevel assay of the target to assess when, how, and to what extent the target elicits change in the behavior.

(3) Determine the intervention(s) that best engage(s) and produces the desired change in the target.

(4) Conduct a RCT to determine whether the intervention changes the behavior via its effect on the target.

\section{Step 1: Empathic Processes as Putative Target(s) for Intervention}

The qualitative and quantitative research on $\operatorname{MSDP}(3,5,6,27)$ and individual studies linking maternal fetal attachment and empathic processes with smoking cessation among pregnant women described in Sections "Other-Oriented Concern As a Putative Target for Behavior Change Interventions," "Models of Caregiving Behavior," "Specific Processes That Facilitate Caregiving," "How Addictive Processes May Interact with Caregiving Processes," and "Evidence for the Malleability of Empathic Processes," above $(20,72,87)$ provide the empirical foundation for empathic processes as putative targets for intervention.

\section{Step 2: Development of a Multilevel Empathy Assessment Battery}

To ensure valid measurement of target engagement in intervention trials, incorporation of reported, behavioral, neuroimaging, and biological measures is ideal (21). Measures that most robustly and reliably either: (a) differentiate spontaneous quitters and persistent smokers and/or (b) predict the degree of change in smoking should be selected for use in a multilevel assay.

\section{Behavioral Measures}

Empathic processes assessed using behavioral paradigms of affective empathy (images of others' pain), other measures of social cognition such as face emotion processing and parental attachment paradigms (infant cues) should be examined in relation to prospectively assessed biochemically verified patterns of smoking behavior across pregnancy. Incorporation of neuroimaging during the administration of performance-based measures would be ideal as it could verify target engagement at the neuroanatomical level. Different imaging approaches offer different benefits and liabilities. While fMRI would provide optimal spatial resolution, it is more costly, less convenient, and may be less acceptable to pregnant women (138). EEG/ERP is more feasible and provides optimal temporal resolution, but poor spatial resolution. Finally, directly observed measures of empathic behavior such as a social discounting task previously linked to MSDP (139) and postpartum observations of mother-infant interactions (140) may also be useful.

\section{Biological Measures}

Non-invasive physiologic tests can detect the magnitude of general affective responding to stimuli presented in behavioral paradigms. Vagal (parasympathetic) tone is a non-specific measure of a range of health-related outcomes including compassion for the suffering of others (141), ascertained through heart rate variability from electrocardiographic monitoring. Electrodermal monitoring detects changes in skin conductance associated with acute sympathetic responses to stress delivered by experimental stimuli. Measurement of peripheral oxytocin and cortisol levels at baseline and before and after an experimental stimulus could be useful as an additional biological measure of empathic and stress responding. However, a number of methodologic challenges related to pulsatile release and diurnal variation need to be carefully considered in study design and interpretation of results $(142,143)$.

\section{Other Methodological Considerations}

The multilevel assay for empathic processes should be conducted in a sample of pregnant smokers who quit following recognition of pregnancy and those who did not, ideally matched on demographic and other characteristics associated with MSDP, and beginning as early in pregnancy as possible. Assessment of empathy prior to conception, for example, in a population of sexually active smokers of child-bearing age would be ideal, but challenging. Conducting the assay for empathy-related processes three or more times across gestation would enable the assessment of change across pregnancy. Measures that most robustly differentiate quitters from persistent smokers or relate to the degree of change (for example, reduction in cigarettes per day following recognition of pregnancy) should be selected for use in tests of target engagement, evaluation of interventions, and eventually, full efficacy trials.

We stress the importance of examining continuous measures of smoking and more nuanced smoking patterns beyond standard categorizations (i.e., number of quit attempts among those not achieving sustained abstinence and the degree of reduction or increase) to not only capture fluctuation in smoking (45) but also 
to quantify efforts made to change behavior. Timeline follow back methods (interview or computer-assisted) to capture daily smoking (144) combined with periodic cotinine verification adjusted for trimester of pregnancy (145) and reporting error (146) remains the gold standard for prenatal smoking assessments.

Ecological momentary assessment (EMA) is a popular tool that provides extremely fine-grained information about constructs of interest in relation to behavior (147). However, EMA activities could serve as a cue that influences smoking behavior similar to the way that behavior monitoring approaches (i.e., food diaries) can change behavior over time (148). This could limit the validity of data collected for observational purposes. Wireless physiologic monitoring devices now widely available (149), however, might be a feasible approach to monitoring biomarkers such as vagal tone and stress reactivity in conjunction with periodic reports since these devices can record data continuously with minimal action required by the wearer.

\section{CONCLUSION: A CALL TO ACTION ON PRENATAL PREVENTIVE INTERVENTION}

A mother's behavior during pregnancy is arguably the most robust modifiable determinant of the intrauterine environment, increasingly recognized as a critical contributor to the lifelong health of her unborn child $(150,151)$. In this way, improving the impact of prenatal intervention constitutes a far-reaching preventive investment (152). The challenges of behavior change, even during the uniquely opportune window of pregnancy, however, are substantial and felt by pregnant women, their health-care providers, and intervention scientists alike. Pregnant women who smoke and use other addictive substances face enormous biopsychosocial risks that are often perpetuated intergenerationally. These risks compound the effects of smoking on mothers' own health and the health of their families. A deeper mechanistic understanding of MSDP that transcends interdisciplinary divisions to leverage scientific advances generated from multiple perspectives and theoretical foundations is proposed to most effectively and efficiently address this major public health problem.

We underscore the importance of scientific progress on MSDP made in the past 40 years. Intervention is associated with increases in birth weight even when total abstinence is not achieved. Moreover, interventions that provide financial incentives for confirmed abstinence (the most effective approach to date) are clearly cost-saving when considering the neonatal health-care costs saved $(3,10)$. But this may not be a satisfactory solution.

\section{REFERENCES}

1. Johnson CD, Jones S, Paranjothy S. Reducing low birth weight: prioritizing action to address modifiable risk factors. J Public Health (2017) 39(1):122-31. doi:10.1093/pubmed/fdv212

2. Donovan JW. Randomised controlled trial of anti-smoking advice in pregnancy. Br J Prev Soc Med (1977) 31(1):6-12.

3. Chamberlain C, O'Mara-Eves A, Oliver S, Caird JR, Perlen SM, Eades SJ, et al. Psychosocial interventions for supporting women to stop smoking in pregnancy. Cochrane Database Syst Rev (2013) 10:CD001055. doi:10.1002/14651858.CD001055.pub4
The long-term ethical, policy, and personal implications of widespread financial incentive-based interventions for MSDP are unknown. Perceptions regarding the use of public resources for these interventions could compound the stigma and marginalization already felt by populations disproportionately affected by MSDP leading to more harm than benefit (6). Moreover, reducing prenatal smoking exposure alone may not reduce children's longterm mental health risks. Unlike animal models, in which prenatal nicotine exposure has demonstrated clear and causal effects on offspring brain development, causality in humans has not been established due to numerous confounders linking MSDP with child outcomes (153). Genetically informed studies designed to disentangle prenatal exposure from familial factors suggest that the independent effect of MSDP on neurodevelopmental risk is either very small $(154,155)$ or absent $(156,157)$.

What is clear is that families transmit mental health riskthrough genes, parenting behavior, the rearing environment, and their complex interactions. This means that improving long-term mental health outcomes in children exposed to MSDP requires modification of maternal behaviors other than smoking. The proposed developmental framework which embeds MSDP within the greater landscape of the maternal-child relationship is an important step toward characterizing the insidious processes for which MSDP may simply be a marker. Even a minute possibility for successful preventive intervention justifies scientific investment and collaboration when the risks associated with the status quo are so high and so far-reaching.

\section{AUTHOR CONTRIBUTIONS}

SM drafted the initial manuscript. SM, JD, KW, and LW made substantial contributions to the conception of this manuscript, revising it critically for important intellectual content, and provided final approval for the current version to be published. All authors agreed to be accountable for all aspects of the work in ensuring that questions related to the accuracy or integrity of any part of the work are appropriately investigated and resolved.

\section{FUNDING}

Research reported in this publication was supported by the National Institute on Drug Abuse of the National Institutes of Health under Award Number K23DA037913 to SM. The content is solely the responsibility of the authors and does not necessarily represent the official views of the National Institutes of Health.

4. Lumley J, Chamberlain C, Dowswell T, Oliver S, Oakley L, Watson L. Interventions for promoting smoking cessation during pregnancy. Cochrane Database Syst Rev (2009) 3:CD001055. doi:10.1002/14651858.CD001055. pub3

5. Graham H, Flemming K, Fox D, Heirs M, Sowden A. Cutting down: insights from qualitative studies of smoking in pregnancy. Health Soc Care Community (2014) 22(3):259-67. doi:10.1111/hsc.12080

6. Flemming K, Graham H, Heirs M, Fox D, Sowden A. Smoking in pregnancy: a systematic review of qualitative research of women who commence pregnancy as smokers. JAdv Nurs (2013) 69(5):1023-36. doi:10.1111/ jan. 12066 
7. Tong VT, Dietz PM, Morrow B, D’Angelo DV, Farr SL, Rockhill KM, et al. Trends in smoking before, during, and after pregnancy-pregnancy risk assessment monitoring system, United States, 40 sites, 2000-2010. MMWR Surveill Summ (2013) 62(6):1-19.

8. Ncube CN, Mueller BA. Daughters of mothers who smoke: a population-based cohort study of maternal prenatal tobacco use and subsequent prenatal smoking in offspring. Paediatr Perinat Epidemiol (2017) 31(1):14-20. doi:10.1111/ppe.12330

9. Jones M, Lewis S, Parrott S, Wormall S, Coleman T. Re-starting smoking in the postpartum period after receiving a smoking cessation intervention: a systematic review. Addiction (2016) 111(6):981-90. doi:10.1111/add.13309

10. Higgins ST, Solomon LJ. Some recent developments on financial incentives for smoking cessation among pregnant and newly postpartum women. Curr Addict Rep (2016) 3(1):9-18. doi:10.1007/s40429-016-0092-0

11. Lushniak BD, Samet JM, Pechacek TF, Norman LA, Taylor PA. The Health Consequences of Smoking-50 Years of Progress: A Report of the Surgeon General. Rockville, MD (2014).

12. Rosenstock IM. Why people use health services. Milbank Mem Fund $Q$ (1966) 44:94-124. doi:10.2307/3348967

13. Michie S, Richardson M, Johnston M, Abraham C, Francis J, Hardeman W, et al. The behavior change technique taxonomy (v1) of 93 hierarchically clustered techniques: building an international consensus for the reporting of behavior change interventions. Ann Behav Med (2013) 46(1):81-95. doi:10.1007/s12160-013-9486-6

14. Mokdad AH, Marks JS, Stroup DF, Gerberding JL. Actual causes of death in the United States, 2000. JAMA (2004) 291(10):1238-45. doi:10.1001/ jama.291.10.1238

15. Yoon PW, Bastian B, Anderson RN, Collins JL, Jaffe HW; Centers for Disease Control and Prevention (CDC). Potentially preventable deaths from the five leading causes of death-United States, 2008-2010. MMWR Morb Mortal Wkly Rep (2014) 63(17):369-74.

16. Flegal KM, Carroll MD, Kuczmarski RJ, Johnson CL. Overweight and obesity in the United States: prevalence and trends, 1960-1994. Int J Obes (1998) 22(1):39-47. doi:10.1038/sj.ijo.0800541

17. Flegal KM, Kruszon-Moran D, Carroll MD, Fryar CD, Ogden CL. Trends in obesity among adults in the United States, 2005 to 2014. JAMA (2016) 315(21):2284-91. doi:10.1001/jama.2016.6458

18. Ershoff DH, Quinn VP, Boyd NR, Stern J, Gregory M, Wirtschafter D. The Kaiser Permanente prenatal smoking-cessation trial: when more isn't better, what is enough? Am J Prev Med (1999) 17(3):161-8. doi:10.1016/ S0749-3797(99)00071-9

19. Stotts AL, Diclemente CC, Carbonari JP, Mullen PD. Pregnancy smoking cessation: a case of mistaken identity. Addict Behav (1996) 21(4):459-71. doi:10.1016/0306-4603(95)00082-8

20. Massey SH, Bublitz MH, Magee SR, Salisbury A, Niaura RS, Wakschlag LS, et al. Maternal-fetal attachment differentiates patterns of prenatal smoking and exposure.AddictBehav (2015) 45:51-6.doi:10.1016/j.addbeh.2015.01.028

21. Riddle M. News from the NIH (Science of Behavior Change Working Group): using an experimental medicine approach to facilitate translational research. Transl Behav Med (2015) 5(4):486. doi:10.1007/s13142-0150333-0

22. Sheeran P, Klein WM, Rothman AJ. Health behavior change: moving from observation to intervention. Annu Rev Psychol (2017) 68:573-600. doi:10.1146/annurev-psych-010416-044007

23. Fiore M, Jaen CR, Baker T, Bailey W, Benowitz N, Curry SE, et al. Treating Tobacco Use and Dependence: 2008 Update. Rockville, MD: US Department of Health and Human Services (2008).

24. Siu AL. Behavioral and pharmacotherapy interventions for tobacco smoking cessation in adults, including pregnant women: US preventive services task force recommendation statement USPSTF recommendation statement for interventions for tobacco smoking cessation. Ann Intern Med (2015) 163(8):622-34. doi:10.7326/M15-2023

25. Wakschlag LS, Pickett KE, Middlecamp MK, Walton LL, Tenzer P, Leventhal BL. Pregnant smokers who quit, pregnant smokers who don't: does history of problem behavior make a difference? Soc Sci Med (2003) 56(12):2449-60. doi:10.1016/S0277-9536(02)00248-4

26. Weaver K, Campbell R, Mermelstein R, Wakschlag LS. Pregnancy smoking in context: the influence of multiple levels of stress. Nic Tob Res (2008) 10(6):1065-73. doi:10.1080/14622200802087564
27. White TJ, Redner R, Skelly JM, Higgins ST. Examining educational attainment, pre-pregnancy smoking rate, and delay discounting as predictors of spontaneous quitting among pregnant smokers. Exp Clin Psychopharmacol (2014) 22(5):384. doi:10.1037/a0037492

28. Massey SH, Reiss D, Neiderhiser JM, Leve LD, Shaw DS, Ganiban JM. Maternal personality traits associated with patterns of prenatal smoking and exposure: implications for etiologic and prevention research. Neurotoxicol Teratol (2016) 53:48-54. doi:10.1016/j.ntt.2015.11.010

29. Bauld L, Oncken C. Smoking in pregnancy: an ongoing challenge. Nic Tob Res (2017) 19(5):495-6. doi:10.1093/ntr/ntx034

30. Woodby LL, Windsor RA, Snyder SW, Kohler CL, Diclemente CC. Predictors of smoking cessation during pregnancy. Addiction (1999) 94(2):283-92. doi:10.1046/j.1360-0443.1999.94228311.x

31. Curry SJ, McBride C, Grothaus L, Lando H, Pirie P. Motivation for smoking cessation among pregnant women. Psychol Addict Behav (2001) 15(2):126. doi:10.1037/0893-164X.15.2.126

32. Graham H, Hawkins SS, Law C. Lifecourse influences on women's smoking before, during and after pregnancy. Soc Sci Med (2010) 70(4):582-7. doi:10.1016/j.socscimed.2009.10.041

33. Smedberg J, Lupattelli A, Mårdby A-C, Nordeng H. Characteristics of women who continue smoking during pregnancy: a cross-sectional study of pregnant women and new mothers in 15 European countries. BMC Pregnancy Childbirth (2014) 14(1):213. doi:10.1186/1471-2393-14-213

34. Solomon LJ, Quinn VP. Spontaneous quitting: self-initiated smoking cessation in early pregnancy. Nic Tob Res (2004) 6(Suppl 2):S203-16. doi:10.1080 /14622200410001669132

35. Hughes JR, Gulliver SB, Fenwick JW, Valliere WA, Cruser K, Pepper S, et al. Smoking cessation among self-quitters. Health Psychol (1992) 11(5):331. doi:10.1037/0278-6133.11.5.331

36. Cohen S, Lichtenstein E, Prochaska JO, Rossi JS, Gritz ER, Carr CR, et al. Debunking myths about self-quitting: evidence from 10 prospective studies of persons who attempt to quit smoking by themselves. Am Psychol (1989) 44(11):1355. doi:10.1037/0003-066X.44.11.1355

37. Dornelas EA, Sampson RA, Gray JF, Waters D, Thompson PD. A randomized controlled trial of smoking cessation counseling after myocardial infarction. Prev Med (2000) 30(4):261-8. doi:10.1006/pmed.2000.0644

38. Taylor CB, Houston-Miller N, Killen JD, DeBusk RF. Smoking cessation after acute myocardial infarction: effects of a nurse-managed intervention. Ann Intern Med (1990) 113(2):118-23. doi:10.7326/0003-4819-113-2-118

39. Ruggiero L, Tsoh JY, Everett K, Fava JL, Guise BJ. The transtheoretical model of smoking: comparison of pregnant and nonpregnant smokers. Addict Behav (2000) 25(2):239-51. doi:10.1016/S0306-4603(99)00029-5

40. Massey SH, Lieberman DZ, Reiss D, Leve LD, Shaw DS, Neiderhiser JM. Association of clinical characteristics and cessation of tobacco, alcohol, and illicit drug use during pregnancy. Am J Addict (2011) 20(2):143-50. doi:10.1111/j.1521-0391.2010.00110.x

41. Massey SH, Neiderhiser JM, Shaw DS, Leve LD, Ganiban JM, Reiss D. Maternal self concept as a provider and cessation of substance use during pregnancy. Addict Behav (2012) 37(8):956-61. doi:10.1016/j.addbeh.2012.04.002

42. Fergusson DM, Boden JM, Horwood LJ. Transition to parenthood and substance use disorders: findings from a 30-year longitudinal study. Drug Alcohol Depend (2012) 125(3):295-300. doi:10.1016/j.drugalcdep.2012.03.003

43. Pirie PL, Lando H, Curry SJ, McBride CM, Grothaus LC. Tobacco, alcohol, and caffeine use and cessation in early pregnancy. Am J Prev Med (2000) 18(1):54-61. doi:10.1016/S0749-3797(99)00088-4

44. McBride CM, Emmons KM, Lipkus IM. Understanding the potential of teachable moments: the case of smoking cessation. Health Educ Res (2003) 18(2):156-70. doi:10.1093/her/18.2.156

45. Pickett KE, Wakschlag LS, Dai L, Leventhal BL. Fluctuations of maternal smoking during pregnancy. Obstet Gynecol (2003) 101(1):140-7. doi:10.1097/00006250-200301000-00027

46. Tong VT, Jones JR, Dietz PM, D’Angelo D, Bombard JM; Centers for Disease Control and Prevention (CDC). Trends in smoking before, during, and after pregnancy-Pregnancy Risk Assessment Monitoring System (PRAMS), United States, 31 sites, 2000-2005. MMWR Surveill Summ (2009) 58(4):1-29.

47. Windsor RA, Li CQ, Boyd NR Jr, Hartmann KE. The use of significant reduction rates to evaluate health education methods for pregnant smokers: a new harm reduction behavioral indicator? Health Educ Behav (1999) 26(5):648-62. doi:10.1177/109019819902600506 
48. Decety J, Bartal IB-A, Uzefovsky F, Knafo-Noam A. Empathy as a driver of prosocial behaviour: highly conserved neurobehavioural mechanisms across species. Philos Trans R Soc Lond B Biol Sci (2016) 371(1686):20150077. doi:10.1098/rstb.2015.0077

49. Feldman R. The neurobiology of mammalian parenting and the biosocial context of human caregiving. Horm Behav (2016) 77:3-17. doi:10.1016/j. yhbeh.2015.10.001

50. Rutherford HJ, Mayes LC. Parenting and addiction: neurobiological insights. Curr Opin Psychol (2017) 15:55-60. doi:10.1016/j.copsyc.2017.02.014

51. Swain JE, Konrath S, Brown SL, Finegood ED, Akce LB, Dayton CJ, et al. Parenting and beyond: common neurocircuits underlying parental and altruistic caregiving. Parent Sci Pract (2012) 12(2-3):115-23. doi:10.1080/ 15295192.2012.680409

52. Weisman O, Zagoory-Sharon O, Feldman R. Oxytocin administration alters HPA reactivity in the context of parent-infant interaction. Eur Neuropsychopharmacol (2013) 23(12):1724-31. doi:10.1016/j. euroneuro.2013.06.006

53. Decety J. The neural pathways, development and functions of empathy. Curr Opin Behav Sci (2015) 3:1-6. doi:10.1016/j.cobeha.2014.12.001

54. Carter CS. Neuroendocrine perspectives on social attachment and love. Psychoneuroendocrinology (1998) 23(8):779-818. doi:10.1016/ S0306-4530(98)00055-9

55. Young KS, Parsons CE, Stein A, Vuust P, Craske MG, Kringelbach ML. The neural basis of responsive caregiving behaviour: investigating temporal dynamics within the parental brain. Behav Brain Res (2017) 325:105-16. doi:10.1016/j.bbr.2016.09.012

56. Hajcak G, MacNamara A, Olvet DM. Event-related potentials, emotion, and emotion regulation: an integrative review. Dev Neuropsychol (2010) 35(2):129-55. doi:10.1080/87565640903526504

57. Decety J, Jackson PL. A social-neuroscience perspective on empathy. Curr Direct Psychol Sci (2006) 15(2):54-8. doi:10.1111/j.0963-7214.2006.00406.x

58. Davis MH. The effects of dispositional empathy on emotional reactions and helping: a multidimensional approach. J Pers (1983) 51(2):167-84. doi:10.11 11/j.1467-6494.1983.tb00860.x

59. Carter CS. Oxytocin pathways and the evolution of human behavior. Annu Rev Psychol (2014) 65:17-39. doi:10.1146/annurev-psych-010213-115110

60. Eisenberg N, Strayer J, Feshbach ND. Parental empathy and child adjustment/maladjustment. In: Eisenberg N, Strayer J, editors. Empathy and Its Development. New York: Cambridge University Press (1987).

61. Decety J, Jackson PL. The functional architecture of human empathy. Behav Cogn Neurosci Rev (2004) 3(2):71-100. doi:10.1177/1534582304267187

62. Wakschlag L, Perlman S, Blair J, Leibenluft E, Briggs-Gowan M, Pine D. Specifying the neurodevelopmental basis of early childhood disruptive behavior: irritable and callous phenotypes as exemplars. Am J Psychiatry (Forthcoming).

63. Duan C, Hill CE. The current state of empathy research. J Couns Psychol (1996) 43(3):261. doi:10.1037/0022-0167.43.3.261

64. Kim P, Strathearn L, Swain JE. The maternal brain and its plasticity in humans. Horm Behav (2016) 77:113-23. doi:10.1016/j.yhbeh.2015.08.001

65. Swain JE, Dayton C, Kim P, Tolman R, Volling B. Progress on the paternal brain: theory, animal models, human brain research, and mental health implications. Infant Ment Health J (2014) 35(5):394-408. doi:10.1002/ imhj.21471

66. Crandall A, Deater-Deckard K, Riley AW. Maternal emotion and cognitive control capacities and parenting: a conceptual framework. Dev Rev (2015) 36:105-26. doi:10.1016/j.dr.2015.01.004

67. Davidov M, Zahn-Waxler C, Roth-Hanania R, Knafo A. Concern for others in the first year of life: theory, evidence, and avenues for research. Child Dev Perspect (2013) 7(2):126-31. doi:10.1111/cdep.12028

68. Chase-Lansdale PL, Wakschlag LS, Brooks-Gunn J. A psychological perspective on the development of caring in children and youth: the role of the family. J Adolesc (1995) 18(5):515-56. doi:10.1006/jado.1995.1037

69. Constantine NA, Slater JK, Carroll JA, Antin TM. Smoking cessation, maintenance, and relapse experiences among pregnant and postpartum adolescents: a qualitative analysis. J Adolesc Health (2014) 55(2):216-21. doi:10.1016/j.jadohealth.2013.12.027

70. Bakermans-Kranenburg MJ, van IJzendoorn MH. A sociability gene? Metaanalysis of oxytocin receptor genotype effects in humans. Psychiatr Genet (2014) 24(2):45-51. doi:10.1097/YPG.0b013e3283643684
71. Brüne M. Does the oxytocin receptor polymorphism (rs2254298) confer 'vulnerability' for psychopathology or 'differential susceptibility'? Insights from evolution. BMC Med (2012) 10(1):38. doi:10.1186/1741-7015-10-38

72. Massey SH, Estabrook R, O’Brien TC, Pine DS, Burns JL, Jacob S, et al. Preliminary evidence for the interaction of the oxytocin receptor gene (oxtr) and face processing in differentiating prenatal smoking patterns. Neurosci Lett (2015) 584:259-64. doi:10.1016/j.neulet.2014.10.049

73. Numan M. Hypothalamic neural circuits regulating maternal responsiveness toward infants. Behav Cogn Neurosci Rev (2006) 5(4):163-90. doi:10.1177/1534582306288790

74. Bartels A, Zeki S. The neural correlates of maternal and romantic love. Neuroimage (2004) 21(3):1155-66. doi:10.1016/j.neuroimage.2003.11.003

75. Kim S, Strathearn L. Oxytocin and maternal brain plasticity. New Dir Child Adolesc Dev (2016) 2016(153):59-72. doi:10.1002/cad.20170

76. Riem MM, Bakermans-Kranenburg MJ, Pieper S, Tops M, Boksem MA, Vermeiren RR, et al. Oxytocin modulates amygdala, insula, and inferior frontal gyrus responses to infant crying: a randomized controlled trial. Biol Psychiatry (2011) 70(3):291-7. doi:10.1016/j.biopsych.2011.02.006

77. Jackson PL, Meltzoff AN, Decety J. How do we perceive the pain of others? A window into the neural processes involved in empathy. Neuroimage (2005) 24(3):771-9. doi:10.1016/j.neuroimage.2004.09.006

78. Decety J, Lewis KL, Cowell JM. Specific electrophysiological components disentangle affective sharing and empathic concern in psychopathy. J Neurophysiol (2015) 114(1):493-504. doi:10.1152/jn.00253.2015

79. Decety J, Meidenbauer KL, Cowell JM. The development of cognitive empathy and concern in preschool children: a behavioral neuroscience investigation. Dev Sci (2017). doi:10.1111/desc. 12570

80. Ho SS, Konrath S, Brown S, Swain JE. Empathy and stress related neural responses in maternal decision making. Front Neurosci (2014) 8:152. doi:10.3389/fnins.2014.00152

81. Rutherford HJ, Wallace NS, Laurent HK, Mayes LC. Emotion regulation in parenthood. Dev Rev (2015) 36:1-14. doi:10.1016/j.dr.2014.12.008

82. Insel TR, Young LJ. The neurobiology of attachment. Nat Rev Neurosci (2001) 2(2):129-36. doi:10.1038/35053579

83. Swain JE, Kim P, Spicer J, Ho S, Dayton CJ, Elmadih A, et al. Approaching the biology of human parental attachment: brain imaging, oxytocin and coordinated assessments of mothers and fathers. Brain Res (2014) 1580:78-101. doi:10.1016/j.brainres.2014.03.007

84. Cranley MS. Development of a tool for the measurement of maternal attachment during pregnancy. Nurs Res (1981) 30(5):281-4. doi:10.1097/00006199-198109000-00008

85. Feldman R, Weller A, Zagoory-Sharon O, Levine A. Evidence for a neuroendocrinological foundation of human affiliation: plasma oxytocin levels across pregnancy and the postpartum period predict mother-infant bonding. Psychol Sci (2007) 18(11):965-70. doi:10.1111/j.1467-9280.2007. 02010.x

86. Cannella BL. Maternal-fetal attachment: an integrative review. J Adv Nurs (2005) 50(1):60-8. doi:10.1111/j.1365-2648.2004.03349.x

87. Magee SR, Bublitz MH, Orazine C, Brush B, Salisbury A, Niaura R, et al. The relationship between maternal-fetal attachment and cigarette smoking over pregnancy. Matern Child Health J (2014) 18(4):1017-22. doi:10.1007/ s10995-013-1330-x

88. Zeanah CH, Benoit D, Hirshberg L, Barton M, Regan C. Mothers' representations of their infants are concordant with infant attachment classifications. Dev Issues Psychiatry Psychol (1994) 1:9-18.

89. Huth-Bocks AC, Theran SA, Levendosky AA, Bogat GA. A social-contextual understanding of concordance and discordance between maternal prenatal representations of the infant and infant-mother attachment. Infant Ment Health J (2011) 32(4):405-26. doi:10.1002/imhj.20304

90. Vreeswijk CM, Maas AJ, van Bakel HJ. Parental representations: a systematic review of the working model of the child interview. Infant Ment Health J (2012) 33(3):314-28. doi:10.1002/imhj.20337

91. Fonagy P, Target M. Attachment and reflective function: their role in self-organization. Dev Psychopathol (1997) 9(4):679-700. doi:10.1017/ S0954579497001399

92. Meins E, Fernyhough C, Wainwright R, Clark-Carter D, Das Gupta M, Fradley E, et al. Pathways to understanding mind: construct validity and predictive validity of maternal mind-mindedness. Child Dev (2003) 74(4):1194-211. doi:10.1111/1467-8624.00601 
93. Schuetze P, Eiden RD, Dombkowski L. The association between cigarette smoking during pregnancy and maternal behavior during the neonatal period. Infancy (2006) 10(3):267-88. doi:10.1207/s15327078in1003_4

94. Tandon M, Si X, Belden A. Parenting practices in pregnancy smokers compared to non smokers. J Clin Med Res (2013) 5(2):84. doi:10.4021/ jocmr1283w

95. Suchman N, Mayes L, Conti J, Slade A, Rounsaville B. Rethinking parenting interventions for drug-dependent mothers: from behavior management to fostering emotional bonds. J Subst Abuse Treat (2004) 27(3):179-85. doi:10.1016/j.jsat.2004.06.008

96. Slade A, Grienenberger J, Bernbach E, Levy D, Locker A. Maternal reflective functioning, attachment, and the transmission gap: a preliminary study. Attach Hum Dev (2005) 7(3):283-98. doi:10.1080/14616730500245880

97. Pajulo M, Pyykkönen N, Kalland M, Sinkkonen J, Helenius H, Punamäki RL, et al. Substance-abusing mothers in residential treatment with their babies: importance of pre-and postnatal maternal reflective functioning. Infant Ment Health J (2012) 33(1):70-81. doi:10.1002/imhj.20342

98. Rutherford H, Williams S, Moy S, Mayes L, Johns J. Disruption of maternal parenting circuitry by addictive process: rewiring of reward and stress systems. Front Psychiatry (2011) 2:37. doi:10.3389/fpsyt.2011.00037

99. Landi N, Montoya J, Kober H, Rutherford H, Mencl E, Worhunsky P, et al. Maternal neural responses to infant cries and faces: relationships with substance use. Front Psychiatry (2011) 2:32. doi:10.3389/fpsyt.2011.00032

100. Rutherford HJ, Maupin AN, Landi N, Potenza MN, Mayes LC. Current tobacco-smoking and neural responses to infant cues in mothers. Parent Sci Pract (2017) 17(1):1-10. doi:10.1080/15295192.2017.1262176

101. Volkow ND, Baler RD, Goldstein RZ. Addiction: pulling at the neural threads of social behaviors. Neuron (2011) 69(4):599-602. doi:10.1016/j. neuron.2011.01.027

102. Koob GF, Le Moal M. Plasticity of reward neurocircuitry and the 'dark side' of drug addiction. Nat Neurosci (2005) 8(11):1442-4. doi:10.1038/ nn1105-1442

103. Sutherland MT, Riedel MC, Flannery JS, Yanes JA, Fox PT, Stein EA, et al. Chronic cigarette smoking is linked with structural alterations in brain regions showing acute nicotinic drug-induced functional modulations. Behav Brain Funct (2016) 12(1):16. doi:10.1186/s12993-016-0100-5

104. Massey SH, Newmark RL, Wakschlag LS. Explicating the role of empathic processes in substance use disorders: a conceptual framework and research agenda. Drug Alcohol Rev (2017). doi:10.1111/dar.12548

105. Fedota JR, Stein EA. Resting-state functional connectivity and nicotine addiction: prospects for biomarker development. Ann N Y Acad Sci (2015) 1349(1):64-82. doi:10.1111/nyas.12882

106. Sutherland MT, Carroll AJ, Salmeron BJ, Ross TJ, Stein EA. Insula’s functional connectivity with ventromedial prefrontal cortex mediates the impact of trait alexithymia on state tobacco craving. Psychopharmacology (2013) 228(1):143-55. doi:10.1007/s00213-013-3018-8

107. Coleman T, Chamberlain C, Davey MA, Cooper SE, Leonardi-Bee J. Pharmacological interventions for promoting smoking cessation during pregnancy. Cochrane Database Syst Rev (2015) 9:CD010078. doi:10.1002/14651858.CD010078

108. Rollnick S, Miller WR, Butler CC, Aloia MS. Motivational interviewing in health care: helping patients change behavior. COPD J Chron Obstruct Pulmon Dis (2008) 5(3):203.

109. Stotts AL, Groff JY, Velasquez MM, Benjamin-Garner R, Green C, Carbonari JP, et al. Ultrasound feedback and motivational interviewing targeting smoking cessation in the second and third trimesters of pregnancy. Nic Tob Res (2009) 11(8):961-8. doi:10.1093/ntr/ntp095

110. Slade A, Sadler L, De Dios-Kenn C, Webb D, Currier-Ezepchick J, Mayes L. Minding the baby: a reflective parenting program. Psychoanal Study Child (2006) 60(1):74-100. doi:10.1080/00797308.2005.11800747

111. Pajulo M, Suchman N, Kalland M, Mayes L. Enhancing the effectiveness of residential treatment for substance abusing pregnant and parenting women: focus on maternal reflective functioning and mother-child relationship. Infant Ment Health J (2006) 27(5):448-65. doi:10.1002/imhj.20100

112. Suchman NE, DeCoste C, Castiglioni N, McMahon TJ, Rounsaville B, Mayes L. The Mothers and Toddlers Program, an attachment-based parenting intervention for substance using women: post-treatment results from a randomized clinical pilot. Attach Hum Dev (2010) 12(5):483-504. doi:10.1080/14616734.2010.501983
113. Maglione MA, Maher AR, Ewing B, Colaiaco B, Newberry S, Kandrack R, et al. Efficacy of mindfulness meditation for smoking cessation: a systematic review and meta-analysis. Addict Behav (2017) 69:27-34. doi:10.1016/j. addbeh.2017.01.022

114. Li W, Howard MO, Garland EL, McGovern P, Lazar M. Mindfulness treatment for substance misuse: a systematic review and meta-analysis. J Subst Abuse Treat (2017) 75:62-96. doi:10.1016/j.jsat.2017.01.008

115. Weng HY, Fox AS, Hessenthaler HC, Stodola DE, Davidson RJ. The role of compassion in altruistic helping and punishment behavior. PLoS One (2015) 10(12):e0143794. doi:10.1371/journal.pone.0143794

116. Galante J, Galante I, Bekkers M-J, Gallacher J. Effect of kindness-based meditation on health and well-being: a systematic review and meta-analysis. J Consult Clin Psychol (2014) 82(6):1101. doi:10.1037/a0037249

117. Van Cappellen P, Rice EL, Catalino LI, Fredrickson BL. Positive affective processes underlie positive health behaviour change. Psychol Health (2017):1-21. doi:10.1080/08870446.2017.1320798

118. Williams PB, Poljacik G, Decety J, Nusbaum HC. Loving-kindness language exposure leads to changes in sensitivity to imagined pain. J Posit Psychol (2017):1-5. doi:10.1080/17439760.2017.1315648

119. Bakermans-Kranenburg M, Van Ijzendoorn M. Sniffing around oxytocin: review and meta-analyses of trials in healthy and clinical groups with implications for pharmacotherapy. Transl Psychiatry (2013) 3(5):e258. doi:10.1038/tp.2013.34

120. Buisman-Pijlman FT, Sumracki NM, Gordon JJ, Hull PR, Carter CS, Tops M. Individual differences underlying susceptibility to addiction: role for the endogenous oxytocin system. Pharmacol Biochem Behav (2014) 119:22-38. doi:10.1016/j.pbb.2013.09.005

121. Tops M, Koole SL, IJzerman H, Buisman-Pijlman FT. Why social attachment and oxytocin protect against addiction and stress: insights from the dynamics between ventral and dorsal corticostriatal systems. Pharmacol Biochem Behav (2014) 119:39-48. doi:10.1016/j.pbb.2013.07.015

122. McRae-Clark AL, Baker NL, Moran-Santa Maria M, Brady KT. Effect of oxytocin on craving and stress response in marijuana-dependent individuals: a pilot study. Psychopharmacology (2013) 228(4):623-31. doi:10.1007/ s00213-013-3062-4

123. Zhou L, Sun W-L, Young AB, Lee K, McGinty JF, See RE. Oxytocin reduces cocaine seeking and reverses chronic cocaine-induced changes in glutamate receptor function. Int J Neuropsychopharmacol (2015) 18(1):1-11. doi:10.1093/ijnp/pyu009

124. Pedersen CA,Smedley KL, Leserman J,Jarskog LF, RauSW, Kampov-Polevoi A, et al. Intranasal oxytocin blocks alcohol withdrawal in human subjects. Alcoholism (2013) 37(3):484-9. doi:10.1111/j.1530-0277.2012.01958.x

125. Kuypers KP, Dolder PC, Ramaekers JG, Liechti ME. Multifaceted empathy of healthy volunteers after single doses of MDMA: a pooled sample of placebo-controlled studies. JPsychopharmacol (2017) 31(5):589-98. doi:10.1177/0269881117699617

126. Bershad AK, Weafer JJ, Kirkpatrick MG, Wardle MC, Miller MA, de Wit H. Oxytocin receptor gene variation predicts subjective responses to MDMA. Soc Neurosci (2016) 11(6):592-9. doi:10.1080/17470919.2016.1143026

127. Feng C, Lori A, Waldman ID, Binder EB, Haroon E, Rilling J. A common oxytocin receptor gene (OXTR) polymorphism modulates intranasal oxytocin effects on the neural response to social cooperation in humans. Genes Brain Behav (2015) 14(7):516-25. doi:10.1111/gbb.12234

128. Gong P, Fan H, Liu J, Yang X, Zhang K, Zhou X. Revisiting the impact of OXTR rs53576 on empathy: a population-based study and a meta-analysis. Psychoneuroendocrinology (2017) 80:131-6. doi:10.1016/j. psyneuen.2017.03.005

129. Wisner KL. The last therapeutic orphan: the pregnant woman. Am Psychiatr Assoc (2012) 169(6):554-6. doi:10.1176/appi.ajp.2012.12030367

130. Kim P, Leckman JF, Mayes LC, Feldman R, Wang X, Swain JE. The plasticity of human maternal brain: longitudinal changes in brain anatomy during the early postpartum period. Behav Neurosci (2010) 124(5):695. doi:10.1037/ a0020884

131. Roos A, Lochner C, Kidd M, van Honk J, Vythilingum B, Stein DJ. Selective attention to fearful faces during pregnancy. Progr Neuropsychopharmacol Biol Psychiatry (2012) 37(1):76-80. doi:10.1016/j.pnpbp.2011.11.012

132. Roos A, Robertson F, Lochner C, Vythilingum B, Stein DJ. Altered prefrontal cortical function during processing of fear-relevant stimuli in pregnancy. Behav Brain Res (2011) 222(1):200-5. doi:10.1016/j.bbr.2011.03.055 
133. Anderson MV, Rutherford M. Recognition of novel faces after single exposure is enhanced during pregnancy. Evol Psychol (2011) 9(1):147470491100900107. doi:10.1177/147470491100900107

134. HoekzemaE,Barba-MüllerE,Pozzobon C,PicadoM,LuccoF,García-GarcíaD, et al. Pregnancy leads to long-lasting changes in human brain structure. Nat Neurosci (2016) 20:287-96. doi:10.1038/nn.4458

135. DiPietro JA. Psychological and psychophysiological considerations regarding the maternal-fetal relationship. Infant Child Dev (2010) 19(1):27-38. doi:10.1002/icd.651

136. Doyle C, Werner E, Feng T, Lee S, Altemus M, Isler JR, et al. Pregnancy distress gets under fetal skin: maternal ambulatory assessment \& sex differences in prenatal development. Dev Psychobiol (2015) 57(5):607-25. doi:10.1002/ dev.21317

137. von Mohr M, Mayes LC, Rutherford HJ. The transition to motherhood: psychoanalysis and neuroscience perspectives. Psychoanal Study Child (2017) 70(1):154-73. doi:10.1080/00797308.2016.1277905

138. Newmark RL, Zaydlin ML, Yang A, Kuchenrither K, Wisner KL, Massey SH. Obstetric Patients' Perspectives on Functional Magnetic Neuroimaging Research in Pregnant Women. (In review).

139. Bradstreet MP, Higgins ST, Heil SH, Badger GJ, Skelly JM, Lynch ME, et al. Social discounting and cigarette smoking during pregnancy. J Behav Decis Mak (2012) 25(5):502-11. doi:10.1002/bdm.750

140. Lotzin A, Lu X, Kriston L, Schiborr J, Musal T, Romer G, et al. Observational tools for measuring parent-infant interaction: a systematic review. Clin Child Fam Psychol Rev (2015) 18(2):99-132. doi:10.1007/s10567-015-0180-z

141. Stellar JE, Cohen A, Oveis C, Keltner D. Affective and physiological responses to the suffering of others: compassion and vagal activity. J Pers Soc Psychol (2015) 108(4):572. doi:10.1037/pspi0000010

142. McCullough ME, Churchland PS, Mendez AJ. Problems with measuring peripheral oxytocin: can the data on oxytocin and human behavior be trusted? Neurosci Biobehav Rev (2013) 37(8):1485-92. doi:10.1016/j. neubiorev.2013.04.018

143. Brown CA, Cardoso C, Ellenbogen MA. A meta-analytic review of the correlation between peripheral oxytocin and cortisol concentrations. Front Neuroendocrinol (2016) 43:19-27. doi:10.1016/j.yfrne.2016.11.001

144. Sobell LC, Sobell MB. Timeline Followback User's Guide: A Calendar Method for Assessing Alcohol and Drug Use. Toronto: Addiction Research Foundation (1996).

145. Dempsey D, Jacob P, Benowitz NL. Accelerated metabolism of nicotine and cotinine in pregnant smokers. J Pharmacol Exp Ther (2002) 301(2):594-8. doi:10.1124/jpet.301.2.594

146. Dukic VM, Niessner M, Pickett KE, Benowitz NL, Wakschlag LS. Calibrating self-reported measures of maternal smoking in pregnancy via bioassays using a Monte Carlo approach. Int J Environ Res Public Health (2009) 6(6):1744-59.

147. Crosby RD, Lavender JM, Engel SG, Wonderlich SA. Ecological momentary assessment. In: Encyclopedia of Feeding and Eating Disorders (2016). pp. 1-3. doi:10.1007/978-981-287-087-2_159-1

148. Patel MS, Asch DA, Volpp KG. Wearable devices as facilitators, not drivers, of health behavior change. JAMA (2015) 313(5):459-60. doi:10.1001/ jama.2014.14781
149. Laborde S, Mosley E, Thayer JF. Heart rate variability and cardiac vagal tone in psychophysiological research-recommendations for experiment planning, data analysis, and data reporting. Front Psychol (2017) 8. doi:10.3389/ fpsyg. 2017.00213

150. Stinson LJ, Stroud LR, Buka SL, Eaton CB, Lu B, Niaura R, et al. Prospective evaluation of associations between prenatal cortisol and adulthood coronary heart disease risk: the New England family study. Psychosom Med (2015) 77(3):237. doi:10.1097/PSY.0000000000000164

151. Aizer A, Stroud L, Buka S. Maternal stress and child outcomes: evidence from siblings. J Hum Resour (2015) 51(3):523-55. doi:10.3386/w18422

152. Koh HK. A2020 vision for healthy people. NEnglJ Med(2010) 362(18):1653-6. doi:10.1056/NEJMp1001601

153. Knopik VS. Maternal smoking during pregnancy and child outcomes: real or spurious effect? Dev Neuropsychol (2009) 34(1):1-36. doi:10.1080/87565640802564366

154. Estabrook R, Massey SH, Clark CA, Burns JL, Mustanski BS, Cook EH, et al. Separating family-level and direct exposure effects of smoking during pregnancy on offspring externalizing symptoms: bridging the behavior genetic and behavior teratologic divide. Behav Genet (2016) 46(3):389-402. doi:10.1007/s10519-015-9762-2

155. Gaysina D, Fergusson DM, Leve LD, Horwood J, Reiss D, Shaw DS, et al. Maternal smoking during pregnancy and offspring conduct problems: evidence from 3 independent genetically sensitive research designs. JAMA Psychiatry (2013) 70(9):956-63. doi:10.1001/jamapsychiatry. 2013.127

156. D’Onofrio BM, Singh AL, Iliadou A, Lambe M, Hultman CM, Grann M, et al. Familial confounding of the association between maternal smoking during pregnancy and offspring criminality: a population-based study in Sweden. Arch Gen Psychiatry (2010) 67(5):529-38. doi:10.1001/ archgenpsychiatry.2010.33

157. Quinn PD, Rickert ME, Weibull CE, Johansson AL, Lichtenstein P, Almqvist C, et al. Association between maternal smoking during pregnancy and severe mental illness in offspring. JAMA Psychiatry (2017). doi:10.1001/ jamapsychiatry.2017.0456

Conflict of Interest Statement: SM, JD, and LW declare that the research was conducted in the absence of any commercial or financial relationships that could be construed as potential conflicts of interest. The Department of Psychiatry at Northwestern University receives contractual fees for KW consultation to Quinn Emanuel Urquhart \& Sullivan, LLP (New York City), who represent Pfizer Pharmaceutical Company.

Copyright (๑) 2017 Massey, Decety, Wisner and Wakschlag. This is an open-access article distributed under the terms of the Creative Commons Attribution License (CC BY). The use, distribution or reproduction in other forums is permitted, provided the original author(s) or licensor are credited and that the original publication in this journal is cited, in accordance with accepted academic practice. No use, distribution or reproduction is permitted which does not comply with these terms. 